\title{
HYPERLOOP - FUTURE OF TRANSPORT
}

\author{
Vivek Kumar Shrivastav ${ }^{1}$, Sujeet Pandey ${ }^{2}$ \\ ${ }^{1}$ Dept of Aeronautical Engineering, Indian Institute of Kharagpur, Kharagapur, India \\ ${ }^{2}$ Center of Energy Excellence, Gyancity Research Lab, Motihari, India \\ sujeet@gyancity.com, aerovivek91@gmail.com
}

\begin{abstract}
In today's date, orthodox approaches of shipping of people and goods are defined by four modes: rail, road, air, and water. All these modes of transport have faced the issue of either relatively moderate speed (i.e. road and water), pricey (i.e. air), or a combination of both pricey and moderate speed (i.e. rail). Hyperloop is a new mode of transport which confront the paradigm of being fastest and modest at the same time for shipping of people and goods. Hyperloop is an open design concept and theoretically secure, eco-friendly and relatively cheap mode of transport in future.
\end{abstract}

Keywords: Hyperloop, Future Transport, Mode of Transport, Transport

\section{Introduction}

Starting with the wheel, which is being a most important invention of human, we have made a significant progress in science and technology and entered the era of the microprocessor and gained the transportation means like the car, truck, the airplane, ships, etc. To achieve these huge changes in technology we have upgraded the technology time to time but as the time is moving ahead we must also have to upgrade the technology faster rate to bring up more advanced means of transportation. Today's mode of transportation includes: -

i. Roadways (inexpensive, moderate speed, usually not environmentally sound)

ii. Airways (expensive, fast, not environmentally sound)

iii. Railways (expensive, moderate speed, often environmentally sound)

Now there is need of a new mode of transport that has benefits of the current modes without the negative aspects of each mode. This new mode of transportation system should have the following requirements: -

i. Comfortable with the passenger schedule.

ii. Inexpensive (roadways)

iii. Fast (airways)

iv. Eco-friendly (rail/road via electric cars)

v. More Secure

\section{Hyperloop Transport System}

The concept of Hyperloop is given by Elon Musk in 2012. Hyperloop is basically a train traveling at a speed of $760 \mathrm{mph}$ inside a tube having low pressure (figure1). Hyperloop is modern transportation mode which will answer all the human transportation needs but this unique technology gives rise to many questions such as air resistance and friction at high speed, power 
source, and Kantrowitz limit [2]. Answer of all these questions is given very smartly by components and mechanism of Hyperloop.

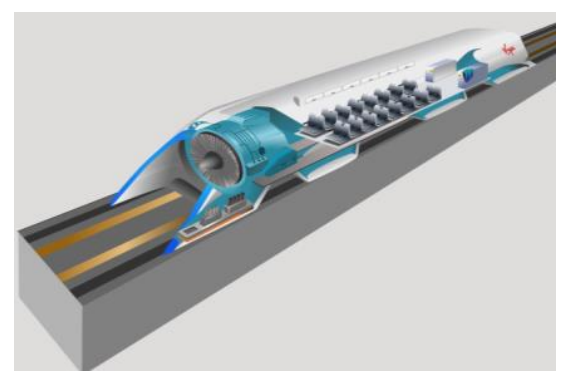

Fig 1: Hyperloop [2]

Hyperloop major components and characteristics which answer the questions are discussed below:

\section{Tube}

The Tube is made of steel. Two tubes will be welded together in a side by side configuration, acting just like the highway, to allow the capsule to travel both directions (figure2). To remove the air resistance offered by air to the train, theoretically meant to have a vacuum inside the tube, but producing the vacuum for the long track is not be achieved by practically. Thus, a very low pressure is maintained inside the tube which offers very negligible air resistance. The expected pressure inside the tube will be maintained around 100 Pascal's which will reduce the drag force of air by 1000 times relative to sea level conditions. When the capsule is traveling inside the tube, air ahead of capsule gets compressed and this increased pressure offered very high resistance to the capsule which can eventually stop the train. This condition is known as Kantrowitz condition [2]. This problem can be solved by adding compressor fan on the front of the train.

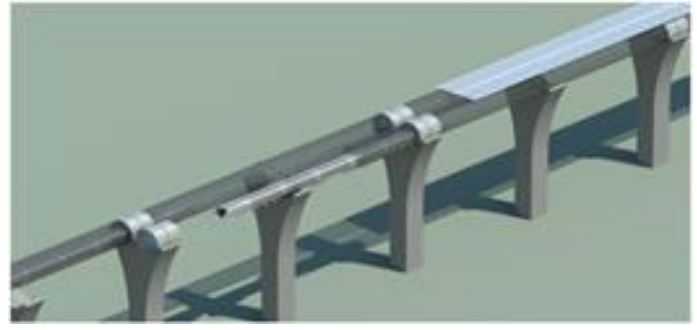

Fig 2: Tube [3-5]

\section{Capsule}

Each capsule carrying 28 passengers travel along the interior of tube depart on average of every 2 minutes from Los Angeles to San Francisco (figure 3).

Certain geometrical changes are brought in capsule design by minimizing frontal surface area for increasing the speed and efficiency.

There are two types of capsules: -

i. Hyperloop Passenger Capsule

ii. Hyperloop Passenger with Capsule 


\section{Compressor Fan}

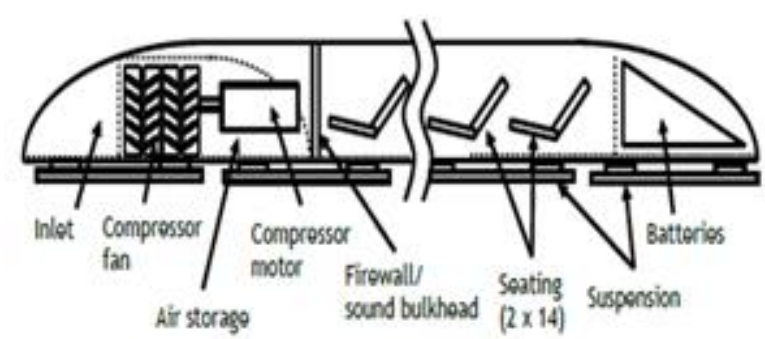

Fig 3: Hyperloop Capsule [3-5]

Compressor Fans are installed on the front of capsules which will suck the accumulated compressed air to nullify the effect of Kantrowitz limit [2] (figure 4).

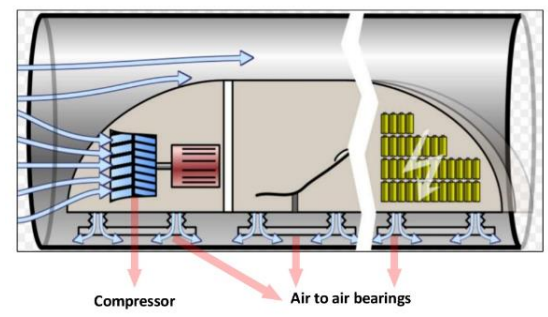

Fig 4: Compressor Fan [3-5]

Compressor fan compresses the air with the compression ratio of 20:1 and supplies the air to air bearing that support the weight of the capsules throughout the journey.

\section{Air Bearing}

Friction was also a major problem for Hyperloop, which was resolved by removing the surface of contact between capsule and tube i.e. capsule should be the float in the air (figure 5). Air bearing provides the suspension to capsules by inhaling the compressed air by the front of capsule's compressor fan [1].
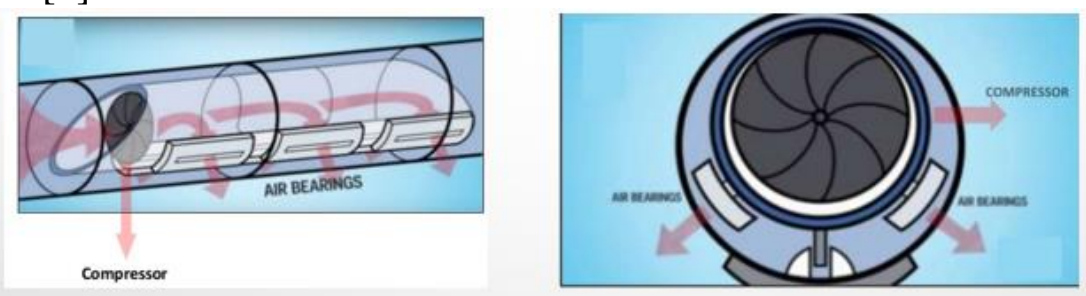

Fig 5: Air Bearing [3-5]

\section{Propulsion}

In order to propel the vehicle at required travel speed, an advanced linear induction motor is used for propelling the Hyperloop capsule at the speed of $760 \mathrm{mph}$ with a maximum of $1 \mathrm{~g}$ for passenger comfort [4]. Stationary motor element (stator) are constructed at various location along the length of the tube to accelerate the capsule while the moving motor element (rotor) is located on the capsules to transfer momentum to the capsule via the linear accelerators (figure 6). 


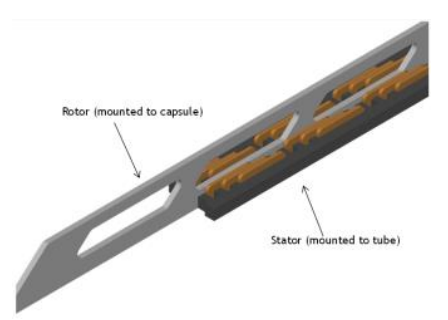

Fig 6: Rotor and Stator 3D Diagram[3-5]

\section{Power Source}

The power requirement for the whole setup of Hyperloop is full-fill by energy produced by the solar panel, which is placed on the tube's roof throughout the track, without consuming a drop of petrol, diesel or kerosene (figure 7). So, it is self-sufficient environment-friendly technology.

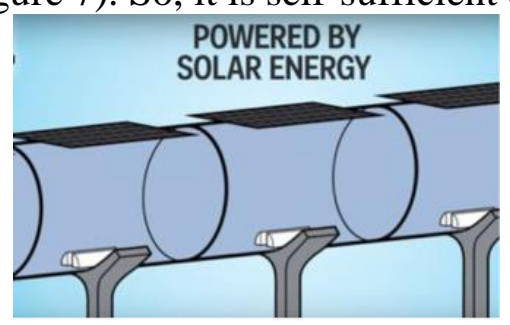

Fig 7: Hyperloop Solar Panel [3-5]

\section{Aerodynamic Analysis of Hyperloop}

For initial stage idea of Hyperloop was proposed for the route between San Francisco, California and Los Angeles covering the distance of 350mile in 35min with an average speed of $600 \mathrm{mph}$. The estimation of the project is $\$ 7.5$ billion USD.

\section{General Flow Analysis}

The flow environment of the tube can be calculated using the following parameters. Speed of sound for calorically perfect gas is given by

$$
v_{e}=(\gamma R T)^{1 / 2}
$$

Mach number of the fluid flowing with velocity $\mathrm{u}_{\mathrm{e}}$ is defined as

$$
M=\frac{u_{e}}{v_{e}}
$$

For the fluid flowing with the density $\rho$, viscosity $\mu$, and fluid velocity $\mathrm{u}_{\mathrm{e}}$, Reynolds's number is defined as

$$
R e=\left(\frac{\rho * u_{e} * h}{\mu}\right)
$$

\section{Aerodynamic Drag Model}

A Simplified geometry of tube and capsule is considered to observe the overall trends of characteristic parameters. $a_{o}$ and $b_{o}$ is considered as the width and height of the tube while $a, b, c$ is considered as width, height, and length of the capsule (figure 8). To maintain the consistency between the model approximation with the dimensions of tube $a_{0}=b_{0}=0.785 D_{\text {tube }}$ is considered which will make the cross-section area of square tube model equal to circular pipe with diameter $\mathrm{D}_{\text {tube. }}$ The capsule is suspended above the bottom of tube by $\mathrm{h}$ (suspension gap height). The blockage ratio, $b_{r}$, is defined as

$$
\left(\frac{a b}{a_{o} b_{o}}\right)=\frac{S A}{S A_{o}}
$$


Where SA and SA 0 are the frontal surface area of the capsule and the yz-cross sectional surface area of the tube, respectively. The following assumptions were made:

i. The capsule will mode only in the x-direction.

ii. The pressure acting on the inner tube in the $\mathrm{z}$-direction is constant and atmospheric molecular mass is neglected.

iii. The capsule is in the centre of the tube.

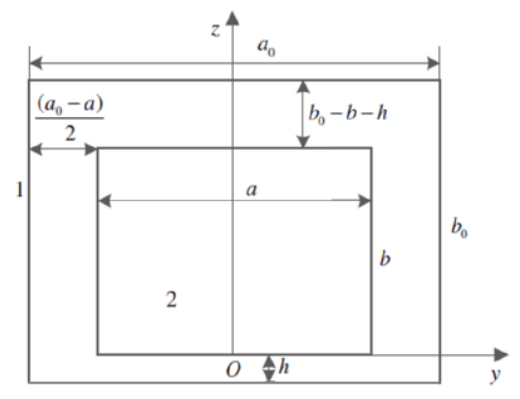

Fig 8: Aerodynamic model of yz cross section of Hyperloop capsule and tube

For the infinitesimal fluid element applying the mass and momentum conservation equation in the $\mathrm{x}$ - direction

$$
\begin{array}{r}
\frac{\partial \rho(x, t)}{\partial t}+\nabla \cdot\left(\rho v_{x}\right)=0 \\
\frac{\partial\left[\rho(x, t) v_{x}\right]}{\partial t}+\nabla \cdot\left[\rho(\mathrm{x}, \mathrm{t}) v_{x}\right] v_{x}=\nabla \cdot\left(\mu \nabla v_{x}\right)+\frac{\partial p}{\partial t}+f_{x}
\end{array}
$$

Where $v_{x}$ is the velocity of the capsule in the $x$-direction, $\rho$ is the density of air in the tube, $\mu$ is dynamics viscosity of the air in the tube, and $f_{x}$ is the external force per unit volume acting on the fluid element in the $\mathrm{x}$-direction. There are three components of drag which are acting on the capsule are considered

i. $\mathrm{F}_{1}$ : for the condition when velocity is greater than the speed of sound, the force acting on the front of capsule due to the collision between air and vehicle.

ii. $\mathrm{F}_{2}$ : force acting due to friction on vehicle face

iii. $\mathrm{F}_{3}$ : the force caused by the pressure difference between the front and rear of the capsule.

\section{Air Bearing Suspension System}

The suspension of the capsule is the major technical challenge of Hyperloop. At a very high speed, using a conventional wheel system would be dynamically unstable which would lead very high vibration and also have very high frictional losses. Another alternative is to use magnetic levitation for the suspension of the capsule but then the cost of material and construction are very high. So for maintaining the expenditure cost to be less, a feasible alternative for suspension of capsule is Air bearing suspension system. In this design, the capsule would sit on the cushion of air which is $0.5 \mathrm{~mm}$ to $1.30 \mathrm{~mm}$ off the tube bottom (figure 9). 


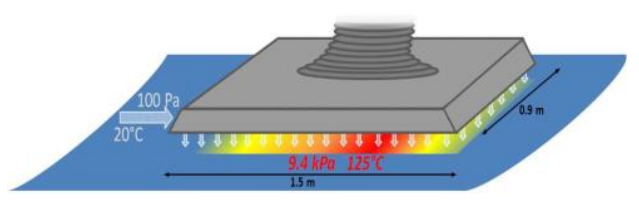

Fig 9: Design of air bearing skis that support the capsule [3-5]

\section{Suspension Gas Flow Characteristics}

\section{a. Gap Temperature}

The average gap temperature can be estimated from adiabatic temperature loss computation,

$$
\begin{gathered}
\left(T_{2}\right)=T_{1}\left(\frac{V_{1}}{V_{2}}\right)^{\gamma-1} \\
=T_{1}\left(\frac{h_{1}}{h_{2}}\right)^{\gamma-1}
\end{gathered}
$$

Where $\mathrm{h}_{1}$ is the distance between the bottom portion of tube and front portion of air bearing,

$$
h_{1}=h_{g a p}+L_{s k i} \sin (\alpha)
$$

Where $\alpha$ is the ski's angle of attack. $h_{2}$ is the distance the back of the air bearing ski is off the bottom of the tube (figure 10),

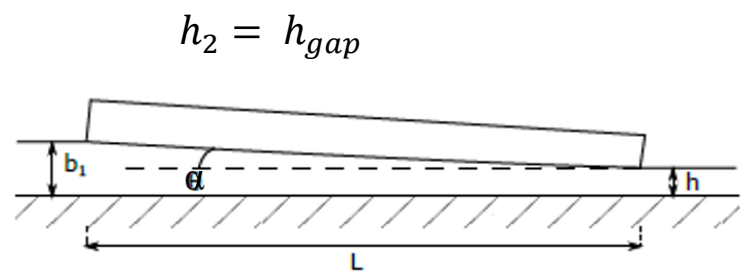

Fig 10: Suspension Pad

The temperature at the ski front $\mathrm{T}_{1}=\mathrm{T}_{\text {tube }}$ and $\mathrm{T}_{2}$ are the temperatures at the ski rear. The average temperature in the gap is thus,

$$
T_{\text {gap }, \text { avg }}=\frac{1}{2} T_{\text {tube }}+\left(\frac{h_{\text {gap }}+L_{\text {ski }} \sin (\alpha)}{h_{\text {gap }}}\right)^{\gamma-1}
$$

Using $\mathrm{T}_{\text {tube }}=293.15 \mathrm{~K}$ and maximum gap, $\mathrm{h}_{\text {gap } \text { max }}$, the adiabatic temperature in the gap would be $\mathrm{T}_{\text {gap }, \text { avg }}=383.45 \mathrm{~K}$.

\section{b. Knudsen Number and Flow Characterization}

As the gap between the tube wall and suspension ski is very small, the value of Knudsen needs to be computed to check the validity of continuum fluid mechanics equation. The Knudsen number is defined as the mean free path between the free stream air molecules $(\lambda)$ divided by the characteristic length through which the gas flows. For the suspension gap flow, the characteristic length is taken to be $h_{\text {gap }}$ and thus

$$
K n=\frac{\lambda}{h_{\text {gap }}}
$$




$$
=\frac{k_{B} T_{\text {gap }}}{\sqrt{2} \pi \sigma^{2} p_{\text {gap }} h_{\text {gap }}}
$$

Where $\mathrm{k}_{\mathrm{B}}$ is Boltzmann constant and $\sigma$ is the particle hard shell mean diameter $\left(=3.7 .10^{-10} \mathrm{~m}\right.$ for air). For the minimum gap height, the largest Knudsen value observed would be 0.002 . Therefore, it is a valid assumption to use continuum fluid mechanics.

\section{Low-pressure Tube}

To have low aerodynamic losses inside the tube, density should be low. The drag force is given by

$$
F_{\text {drag }}=\frac{1}{2} \rho u^{2} A C_{d}
$$

Where $\rho$ is fluid density, $U$ is relative velocity, $A$ is vehicle cross-section area and $C_{d}$ is drag coefficient. The design tube pressure is $100 \mathrm{~Pa}$. For this pressure level, mechanical displacement pump offers the best economy and pumping speed.

\section{Pump Down Time}

The flow environment of the tube can be calculated using the following parameters. For an initial estimate, it will be assumed that the volume flow rate is independent of time. In addition, it is assumed that during pump down of the tube, inflow mass rates are negligible ( $\left.\mathrm{Q}_{\text {in }}<<\mathrm{Q}_{\text {out }}\right)$.

The pressure evolution inside the tube from an initial pressure $\mathrm{p}_{0}$, is given by,

$$
p(t)=p_{o} \exp \left(-\frac{s}{V} t\right)
$$

and time required to reach the final pressure $\mathrm{p}_{1}$

$$
t_{1}=\frac{V}{S} \ln \left(\frac{p_{o}}{p_{1}}\right)
$$

Vacuumizing time is thus directly proportional to tube section volume and inversely proportional to the available vacuumizing speed of the selected pump.

\section{Tube Geometry}

The inner diameter of the tube is $2.23 \mathrm{~m}$ to which is small enough to restrict the material cost at the same time it large enough to provide alleviation of choked flow around the capsule (figure 11). The Tube cross-sectional area is $3.91 \mathrm{~m}^{2}$ giving a capsule/tube area ratio of $36 \%$ or diameter ratio of $60 \%$. It is critical to the aerodynamics of the capsule to keep this ratio as large as possible, even though the pressure in the tube is extremely low.

\section{Route}

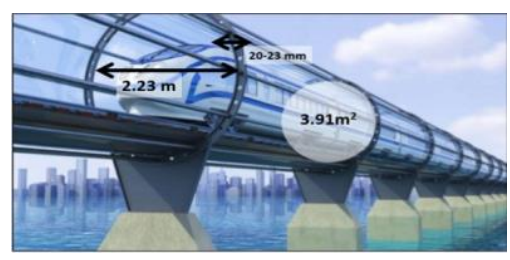

Fig 11: Tube Dimension [3-5]

Throughout the Hyperloop's journey path will need to turn. To ensure passenger comfort, turns will need to be taken at a maximum of $0.5 \mathrm{~g}$ of lateral acceleration.

$$
r_{\min }=\frac{u_{e}^{2}}{0.5 g}
$$

For aerodynamic efficiency, the velocity of the capsule in Hyperloop is typically (figure 12): 


\section{Safety}

a. $480 \mathrm{kph}$ where local geography allows a tube bend $>3.67 \mathrm{~km}$.

b. $760 \mathrm{kph}$ where local geography allows a tube bend $>23.5 \mathrm{~km}$.

Safety of passenger is considered as the prime interest during designing of the Hyperloop. As compared to other transport systems, Hyperloop is a single system that incorporates the vehicle, propulsion system, energy management, timing, and route. Capsules travel in a carefully controlled and maintained tube environment. The system is immune to the wind, ice, fog, and rain. The propulsion system is integrated into the tube is such a way that it can only accelerate the capsule to speeds that are safe in each section. Enough energy storage is available with Linear accelerator to bring all the capsule currently traveling in the Hyperloop tube, safely to stop at their destination in the event of any power outage occurring inside the capsule after it has been launched. If there is an event of any minor leak inside the capsule, the capsule pressure is maintained by an on-board environmental control system which uses the reserve air carried on-board for short period of time it will take to reach the destination.

\section{Present Work}

For initial stage idea of Hyperloop was proposed for the route between San Francisco, California and Los Angeles covering the distance of $350 \mathrm{mile}$ in $35 \mathrm{~min}$ with an average speed of $600 \mathrm{mph}$. The estimation of the project is $\$ 7.5$ billion USD.

\section{Conclusion}

A high-speed transportation system which is also known as Hyperloop is reviewed in this report. Hyperloop could transport people as well vehicles as it has two versions: a passenger-only version and passenger plus vehicle version. By using Hyperloop travel time between Los Angeles and San Francisco can reduce up to $35 \mathrm{~min}$. Hyperloop is much cheaper and faster as compared to train between Los Angeles and San Francisco. The most advantages thing of this system is it doesn't disrupt the current infrastructure which is built along its route. As each and every invention has its limitation, well the same applies to this system which can be minimized with effective use. This concept is efficient for long distances with minimum stoppages, it requires fewer turns for optimum accelerations.

\section{References}

[1] Hyperloop, Train of Future: Vinay Pandey, Shyam Sasi Pallissery (International Journal of Scientific \& Engineering Research, Volume 8, Issue 2, February-2017 ISSN 2229-5518)

[2] A. Kantrowitz, "Proceeding of International Conference of lasers '87" F. J. Duarte, Ed. (STS Press, Mc Lean, VA, 1988).

[3] Hyperloop in OpenMDAO, OpenMDAO, October 9, 2013, Retrieved October 9, 2013.

[4] Musk, Elon (August 12, 2013), Hyperloop Alpha, SpaceX

[5] Hyperloop, Wikipedia 